\title{
O SISTEMA INTERAMERICANO E O DIREITO DA CRIANÇA EM PRESTAR DECLARAÇÕES NO PROCESSO PENAL: GARANTIAS PARA RECONHECIMENTO DE SUA PERSONALIDADE
}

\author{
Daniela Gonçalves Menengoti Ribeiro ${ }^{01^{*}}$ \\ Gustavo Noronha de Ávila ${ }^{02^{* * *}}$ \\ Mayra dos Santos Zavattaro ${ }^{03 * * *}$
}

SUMÁRIO: Introdução; 2 Do dever do ofendido em prestar declarações no Processo Penal; 2.1 Do direito da criança ofendida em prestar declarações no Processo Penal; 30 sistema interamericano de proteção aos direitos humanos $e$ $a$ adesão do Brasil à Corte; 4 As garantias judicias no Sistema interamericana de Proteção aos Direitos Humanos; 4.1 As garantias da criança de ser ouvida no Sistema interamericano e a jurisprudência da Corte; 5 Conclusão; Referências.

RESUMO: O presente artigo investiga a efetiva garantia do direito da criança ofendida de prestar declarações no Processo Penal. A problemática centra-se no reconhecimento da oitiva da criança como um direito, e não como um dever. Esse pressuposto encontra respaldo no entendimento jurídico pátrio, nas convenções internacionais e nos julgados do órgão jurisdicional do Sistema Interamericano de Proteção aos Direitos Humanos. Sendo, pois, um direito, a violação desta garantia dos infantes enseja o acionamento dos mecanismos internacionais de proteção para a efetivação de seus direitos de personalidade previstos na Convenção Interamericana de Direito Humanos (Pacto de San Jose da Costa Rica). O trabalho utiliza o método dedutivo de abordagem e a pesquisa bibliográfica, documental e jurisprudencial como procedimento.

PALAVRAS-CHAVE: Sistema interamericano de proteção aos direitos humanos; Criança; Direito de ser ouvida.

\footnotetext{
Doutora em Direito-Relações Econômicas Internacionais pela Pontifícia Universidade Católica de São Paulo (PUC/SP) com período de pesquisa (doutorado sanduíche) na Université Paris 1, Panthéon-Sorbonne, França. Docente do Programa de Mestrado em Ciências Jurídicas e da graduação em Direito do Centro Universitário de Maringá (UNICESUMAR). Pesquisadora do Instituto Cesumar de Ciência, Tecnologia e Inovação (ICETI). Brasil. E-mail: daniela.menengoti@gmail.com

${ }^{* *}$ Docente do Programa de Mestrado em Ciências Jurídicas e da graduação em Direito do Centro Universitário de Maringá (UNICESUMAR). Pesquisador do Instituto Cesumar de Ciência, Tecnologia e Inovação (ICETI). Brasil.

${ }^{* * *}$ Juíza de Direito do Tribunal de Justiça do Estado do Paraná. Mestranda do Programa de Mestrado em Ciências Jurídicas no Centro Universitário de Maringá (UNICESUMAR). Brasil.
} 


\title{
THE INTER-AMERICAN SYSTEM FOR THE PROTECTION OF HUMAN RIGHTS AND THE RIGHT OF THE CHILDREN TO BE HEARD DURING A CRIMINAL LAWSUIT: GUARANTEES TO RECOGNIZE THEIR PERSONALITY
}

\begin{abstract}
This present paper investigates the effective guarantee of the children and teenagers who are victims of a crime to be heard along the criminal lawsuit against their aggressors. The main problem is to recognize the hearing of the children as a right and not as an obligation. That conclusion is logical based on the Brazilian Law, in the international conventions and in the precedents of the Inter-American Court of Human Rights. Therefore, if the hearing of the children is a right, the violation of this guarantee to be heard provokes the international mechanisms of protection as predicts the International Convention of the Human Rights (San Jose de Costa Rica Pact). The paper uses the deductive method of approach and bibliographical, documentary and jurisprudential research as a procedure.
\end{abstract}

KEY WORDS: Inter-American System for the protection of the Human Rights; Child; The right to be heard.

\section{EL SISTEMA INTERAMERICANO Y EL DERECHO DEL NIÑO EN PRESTAR DECLARACIONES EN EL PROCESO PENAL: GARANTIAS PARA RECONOCIMIENTO DE SU PERSONALIDAD}

RESUMEN: El presente artículo investiga la efectiva garantía del derecho del niño ofendido de prestar declaraciones en el Proceso Penal. La problemática se centra en el reconocimiento de la audición del niño como un derecho, y no como un deber. Ese presupuesto encuentra respaldo en el entendimiento jurídico patrio, en las convenciones internacionales y en los juzgados del órgano jurisdiccional del Sistema Interamericano de Protección a los Derechos Humanos. De ser, pues, un derecho, la violación de esta garantía de los infantes propicia el accionamiento de los mecanismos internacionales de protección a la efectuación de sus derechos de personalidad previstos en la Convención Interamericana de Derecho Humanos (Pacto de San José de Costa Rica). En el estudio se utiliza del método deductivo de abordaje y la investigación bibliográfica, documental y jurisprudencial como procedimiento.

PALABRAS CLAVE: Sistema Interamericano de Protección a los Derechos Humanos; Niños; Derecho de ser escuchada. 


\section{INTRODUÇÃO}

A concepção dos direitos humanos no plano global se deu como fruto de uma lenta formação histórica e de conquistas por meio das lutas pela proteção das sociedades, e teve como marco a Declaração Universal dos Direitos Humanos de 1948, seguida posteriormente pela elaboração do Pacto Internacional dos Direitos Civis e Políticos, e do Pacto Internacional dos Direitos Econômicos, Sociais e Culturais, ambos de 1966.

A Declaração Universal dos Direitos Humanos e os dois pactos constituem a Carta Internacional dos Direitos Humanos e inauguraram, assim, o sistema global de proteção desses direitos, ao lado do qual já se desenhavam os sistemas regionais de proteção, nos âmbitos europeus, interamericano e africano.

O Sistema Interamericano de Proteção dos Direitos Humanos se desenvolveu no curso dos últimos 60 anos, e possibilita, por meio do artigo 44 da Convenção Americana de Direitos Humanos, que qualquer pessoa ou grupo de pessoas, ou entidade não governamental legalmente reconhecida em um ou mais Estadosmembro da Organização dos Estados Americanos, possam apresentar à Comissão petições que contenham denúncias ou queixas de violação desta Convenção por um Estado-parte.

No mesmo documento, é previsto o direito de toda pessoa ser ouvida, em qualquer processo judicial ou administrativo que tenha como pauta algum de seus interesses. $\mathrm{O}$ artigo 19 do diploma enfatiza as garantias da criança e do adolescente, em terem seus interesses defendidos pelo Estado, família e sociedade.

Um dos grandes enunciados dos documentos internacional é o princípio da igualdade, da isonomia, concluindo-se, assim, que os direitos conferidos aos adultos devem ser estendidos às crianças e adolescentes, as quais não podem ser tratadas com discriminação em razão de sua peculiar condição de desenvolvimento.

Tendo em vista o direito de oitiva de todos os interessados no processo, este trabalho busca demonstrar o direito da criança em ser ouvida nos processos penais em que foi vítima, em especial de abuso sexual.

De outro lado, o estudo também se focou na possibilidade de a criança 
acionar a Corte Interamericana de Direitos Humanos no caso de desrespeito desse direito. Ou seja, nos casos de dispensa arbitrária de oitiva da criança nos processos em que é vítima.

Para tanto, será, inicialmente, traçado um panorama do reconhecimento dos direitos e da oitiva da criança como um direito - não dever - tanto no âmbito jurídico nacional quanto em documentos internacionais.

Feito isso, será analisado o Sistema Interamericanos de Direitos Humanos, as garantias judiciais proclamadas na Convenção Americana de Direitos Humanos (Pacto de San Jose da Costa Rica) e os direitos inerentes à criança, considerando para tanto a jurisprudência da Corte Interamericana, reforçando o seu reconhecimento como sujeito de direito, com personalidade e capacidade postulatória, tanto nacional quanto internacionalmente.

\section{DO DEVER DO OFENDIDO EM PRESTAR DECLARAÇÕES NO PROCESSO PENAL}

O processo penal, conforme formulado no direito brasileiro, apenas espera da vítima sua cooperação para a persecução penal e identificação do ofensor, não se preocupando com ela como sujeito de direitos ou sua vontade ou aversão de participação ou não da ação e da condenação do indivíduo ${ }^{04}$.

Não raro as vítimas se sentem ignoradas, negligenciadas ou até agredidas pelo processo penal. Isto acontece em parte devido à definição jurídica do crime, que não inclui a vítima. O crime é definido como ato cometido contra o Estado, e por isso o Estado toma o lugar da vítima no processo. No entanto, em geral as vítimas têm uma série de necessidades a serem atendidas pelo processo judicial. ${ }^{05}$

De acordo com o artigo 201 do Código de Processo Penal, o ofendido será ouvido sempre que possível. $\mathrm{O} \S 1^{\circ}$ do mesmo dispositivo coloca da possibilidade de condução coercitiva do ofendido até à autoridade policial ou judicial em caso de recusa de comparecimento espontâneo, quando intimado a prestar declarações.

${ }^{04}$ BARROS, Flaviane de Magalhães. A participação da vítima no processo penal. Rio de Janeiro: Lumen Juris, 2008, p. 101.

${ }^{05}$ ZEHR, Howard. Justiça Restaurativa. São Paulo: Palas Athena, 2012, p. 24/25. 
A importância de suas declarações se estampa no artigo 400 do mesmo diploma, segundo o qual o ofendido será o primeiro a ser ouvido ao se iniciar a audiência de instrução.

Destaca-se a importância do depoimento do ofendido, em especial para apuração de crimes cometidos na surdina, sem testemunhas oculares, tais quais os crimes contra a dignidade sexual. Ao comentar sobre o ofendido, colocam Eugênio Pacelli e Douglas Fischer: "Não tem ele, por exemplo, direito ao silêncio; ao contrário, tem o dever de depor, enquanto e nas situações em que tenha partido dele a identificação do acusado" 06 .

A doutrina caminha nesse sentido, trazendo a hipótese, inclusive, da determinação de ofício da oitiva do ofendido por parte do magistrado caso esse não seja arrolado pelas partes. Guilherme de Souza Nucci coloca da nulidade relativa do processo penal em que não se ouve o ofendido, caso esse não esteja em local incerto ou falecido, pois haveria prejuízo à instruçãa ${ }^{07}$. Justifica-se o entendimento com base no princípio da verdade real, segundo o qual é vedado se contentar, no processo penal, com os meros fatos apresentados nos autos de ação penal, devendo as partes e o magistrado buscarem todas as circunstâncias ocorridas na realidade ${ }^{08}$. A jurisprudência dos Tribunais nacionais se firma, até o presente momento, no mesmo sentido:

APELAÇ̃̃O CRIMINAL. DESOBEDIÊNCIA. ART. 330 DO CÓDIGO PENAL. VÍTIMA FALTOSA. ATIPICIDADE. Deixando a vítima de comparecer à audiência para a qual foi intimada, abre-se ao magistrado a possibilidade de determinar a condução coercitiva desta, bem como de impor ao faltoso o pagamento da multa e das custas decorrentes do ato, tal como facultam os artigos 201 e 219 do CPP. [...]. ${ }^{09}$

Conclui-se, por ora, pelo dever do ofendido em depor, ao longo dos atos do inquérito e da ação penal, a fim de identificar o seu ofensor e possibilitar a sua

\footnotetext{
${ }^{06}$ PACELLI, Eugênio; FISCHER, Douglas. Comentários ao Código de Processo Penal e sua jurisprudência. São Paulo: Atlas, $5^{a}$ edição, 2013, p. 417.

${ }^{07}$ NUCCI, Guilherme de Souza. Código de processo penal comentado. São Paulo: RT, 2012, p. 463.

${ }^{08}$ BEDÊ JUNIOR, Américo; SENNA, Gustavo. Princípios do processo penal. São Paulo: RT, 2009, p. 102.

${ }^{09}$ Recurso Crime No 71005438023, Turma Recursal Criminal, Turmas Recursais, Relator: Luiz Antônio Alves Capra, Julgado em 09.nov.2015. No mesmo sentido tem-se o julgado: "Habeas corpus crime. Tentativa de homicídio qualificado. Excesso de prazo na formação da culpa. Inocorrência. Aplicação do princípio da razoabilidade. Necessidade de condução coercitiva para oitiva da vitima. Busca da verdade real. Demora justificada. Constrangimento ilegal não caracterizado. Ordem denegada.” In: Tribunal de Justiça do Paraná.

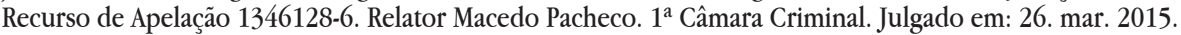


punição pelo Estado, uma vez que, praticado um crime, passa a ser interesse estatal a retribuição por esse. Porém, pergunta-se: mas e quando a vítima é uma criança? Para essas vítimas, a oitiva são um direito.

\subsection{DO DIREITO DA CRIANÇA OFENDIDA EM PRESTAR DECLARAÇÕES NO PROCESSO PENAL}

A necessidade de proporcionar à criança uma proteção especial foi enunciada na Declaração de Genebra de 1924 sobre os Direitos da Criança e na Declaração dos Direitos da Criança adotada pela Assembleia Geral da ONU em 20 de novembro de 1959.

Em 1989 a Organização das Nações Unidas aprovou a Convenção sobre os Direitos das Crianças, no qual estabeleceu novos paradigmas de proteção à infância e à adolescência, reconhecendo-as como sujeitos de direitos titulares da proteção integral. A Convenção foi promulgada no Brasil pelo Decreto $n^{\circ}$. 99.710/1990, por meio da qual o país assume, em razão da força jurídica vinculante do tratado, assegurar sua aplicação a cada criança sujeita à sua jurisdição, sem distinção alguma.

Dentre compromissos assumidos pelos países está o de garantir que "[...] se proporcionará à criança, em particular, a oportunidade de ser ouvida em todo processo judicial ou administrativo que afete a mesma, $[\ldots]^{\prime 10}$. Interpretando o dispositivo, a Organização das Nações Unidas menciona que

A criança não pode ser ouvida efetivamente em ambiente intimidador, hostil, insensível ou inapropriado para sua idade. Os procedimentos devem ser acessíveis e apropriados para uma criança. É necessária atenção especial para provisão e conferência das informações de forma que a criança entenda, com o adequado aparato, profissionais treinados, tribunais adaptados, incluindo a vestimenta de juízes e advogados, e salas de espera separadas. ${ }^{11}$ (tradução livre)

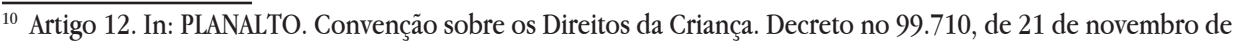
1990. Disponível em: < http://www.planalto.gov.br/ccivil_03/decreto/1990-1994/D99710.htm > . Acesso em: 06.set. 2016.

11 "Provide training on article 12, and its application in practice, for all professionals working with, and for, children, including lawyers, judges, police, social workers, community workers, psychologists, caregivers, residential and prison officers, teachers at all levels of the educational system, medical doctors, nurses and other health professionals, civil servants and public officials, asylum officers and traditional leaders". In: UNITED NATIONS. Committee on the Rights of the child. Fifty-first session Geneva, 25 May-12 June 2009. Disponível em: <http://www2.ohchr.org/english/bodies/crc/docs/AdvanceVersions/CRC-C-GC-12.pdf> . Acesso em: 16. set. 2016, p. 12.
} 
Quando a criança se trata da vítima de um fato criminoso, sua oitiva será essencial para o esclarecimento e responsabilização do ofensor no âmbito penal. Todavia, em se tratando o ofendido de criança, sua oitiva se torna mais delicada, inclusive tendo em vista o elevado número de casos em que o agressor é pessoa próxima da criança, muitas vezes parte da família.

Neste sentido, a socióloga francesa Irène Thèry considera que ao exercer $o$ direito de testemunhar, mesmo com cautelas na sua escuta, a criança perde o direito à infância, exercendo funções que são de responsabilidade dos adultos. A autora alega que essa prática denuncia a proteção da criança como forma moderna de opressão e sugere uma maior participação da família nos processos, para zelar pelos direitos desses "pequenos homens" que se encontram em condições peculiares de desenvolvimento. ${ }^{12}$

Importante destacar que antes da entrada em vigor da Lei $\mathrm{n}^{0}$. 8.069/90, intitulada Estatuto da Criança e do Adolescente, o Código de Menores tratava daqueles que ainda não haviam completado 18 anos apenas quando em "situação irregular" ${ }^{13}$ A criança e o adolescente, antes da adequação da legislação, não eram tidos como sujeitos de direito, mas meros objetos de direito.

Essa situação se alterou com a promulgação da Constituição da República de 1988 e também com a internalização dos documentos internacionais prevendo a prioridade da criança e adolescente - pessoas em situação especial de desenvolvimento. De acordo com Eduardo Rezende Melo, as políticas marxista e feminista foram fundamentais para essa mudança até o caminho da doutrina da proteção integral, uma vez que seus estudos acerca do papel de cada um na sociedade também envolve o papel da criança e adolescente ${ }^{14}$.

O artigo $8^{\circ}$, item 1, alínea "c" do Protocolo Facultativo à Convenção sobre os Direitos da Criança referente à venda de crianças, à prostituição infantil e à pornografia infantil adotado em Nova York em 25 de maio de 2000, prevê, como dever do Estado signatário.

\footnotetext{
${ }_{12}$ THÈRY, Irene. Nouveaux droits de l'enfant, la potion magique? Paris: Esprit, n. 180 (3/4) (mars-avril 1992), pp. $5-30$.

${ }^{13}$ No mesmo sentido, a Opinião Consultiva OC-17/2002, de agosto de 2002 entendeu que criança "é toda pessoa que não tenha completado 18 anos de idade". In: CorteIDH. Opinión Consultiva OC-17/2002 de e 28 de agosto de 2002, Solicitada por la Comisión Interamericana de Derechos Humanos. Disponível em: <http:/ www.corteidh.or.cr/docs/opiniones/seriea_17_esp.pdf > . Acesso em: 20.set.2016.

${ }^{14}$ MELO, Eduardo Rezende. Crianças e adolescentes vítimas de abuso sexual e o direito. Uma análise crítica dos modelos de intervenção e da titulação a direitos sob o crivo histórico-comparativo à luz do debate em torno do depoimento especial. In: Depoimento especial de crianças e adolescente. Porto Alegre: Livraria do advogado, 2016, p. 61.
} 
1. Os Estados Partes adotarão as medidas apropriadas para proteger os direitos e interesses de crianças vítimas das práticas proibidas pelo presente Protocolo em todos os estágios do processo judicial criminal, em particular: [...] que as opiniões, necessidades e preocupações das crianças vitimadas sejam apresentadas e consideradas nos processos em que seus interesses pessoais forem afetados, de forma coerente com as normas processuais da legislação nacional. ${ }^{15}$

Verifica-se, da leitura dos documentos que, em se tratando de ofendido ainda criança, a sua oitiva no processo penal não é tratada como dever. Não é prevista qualquer medida coercitiva ou obrigatória para a sua apresentação até a autoridade. De outro lado, sua oitiva e a valoração de sua opinião é claramente colocada como um direito da criança. Veja-se que

Com efeito, quando uma norma estipula determinado direito, coloca o sujeito em determinada relação com outras pessoas e com o Estado inclusive, conformando as relações entre eles. Quando uma norma prevê que determinado sujeito tem direito sobre algo ou em relação a algo, coloca-o em uma posição jurídica que the permite exigir a satisfação desse direito. ${ }^{16}$

Ao se analisar a evolução do direito da criança e do adolescente, em especial com a implantação da doutrina da proteção integral e prioridade absoluta das políticas públicas envolvendo a criança e o adolescente, não é suficiente o mero reconhecimento dos direitos que lhe são positivados. Nos termos do artigo $226 \mathrm{da}$ Constituição da República cabe ao Estado, à família e à sociedade assegurarem o efetivo exercício dos direitos conferidos a essas pessoas em especial condição de desenvolvimento. Imperioso garantir que a criança de fato ocupe o lugar que lhe é conferido na sociedade e, no caso, no processo penal que trata diretamente de seus interesses. Com isso, conclui José Antônio Daltoé Cezar,

Vê-se, assim, que ouvir a criança nos processos que lhe

${ }_{15}$ PLANALTO. Protocolo Facultativo à Convenção sobre os Direitos da Criança referente à venda de crianças, à prostituição infantil e à pornografia infantil. Decreto no 5.007 , de 8 de março de 2004 . Disponível em: < http:// www.planalto.gov.br/ccivil_03/_ato2004-2006/2004/decreto/d5007.htm >. Acesso em: 20. set. 2016.

${ }^{16}$ MELO, Eduardo Rezende. Crianças e adolescentes vítimas de abuso sexual e o direito. Uma análise crítica dos modelos de intervenção e da titulação a direitos sob o crivo histórico-comparativo à luz do debate em torno do depoimento especial. In: Depoimento especial de crianças e adolescente. Porto Alegre: Livraria do advogado, 2016, p. 68. 
digam respeito, não se trata de mera faculdade da autoridade judiciária, ou prerrogativa do acusado de abuso na produção da prova, mas de um direito dessa mesma criança, que está expressamente estabelecido no ordenamento jurídico, e que deverá, verificada a sua condição peculiar de pessoa em desenvolvimento, ser realizada de forma profissional e acolhedora, sem que se transforme esse mesmo direito em prejuízo para ela ${ }^{17}$.

O direito da criança a ser ouvida, conceder sua opinião e falar sobre o trauma que sofreu quando vítima de um crime abrange a necessidade de o ofendido em reconstruir sua autoestima e expressar sua emoção, garantindo que possa superar o ocorrido e reduzir os danos que lhe foram causados ${ }^{18}$.

Em se tratando de um direito, reconhecido pela legislação interna e por meio de documentos internacionais, e tendo sido negada à criança a oportunidade de falar sobre sua experiência como vítima dentro do processo criminal em que seu suposto ofensor é julgado, esta poderá se amparar no Sistema Interamericano de Proteção aos Direitos Humanos.

Visando a viabilizar o exercício desse direito pela criança, e afastar as críticas diante da ausência de regulamentação legal para a adequada colheita da declaração da criança dentro de um processo judicial, o legislador brasileiro editou a Lei n. 13.431, publicada em 04 de abril de 2017, com previsão de entrada em vigor um ano após a sua publicação. A escuta "qualificada" da criança, foi assim definida pela nova Lei:

Art. 9o A criança ou o adolescente será resguardado de qualquer contato, ainda que visual, com o suposto autor ou acusado, ou com outra pessoa que represente ameaça, coação ou constrangimento.

Art. 10. A escuta especializada e o depoimento especial serão realizados em local apropriado e acolhedor, com infraestrutura e espaço físico que garantam a privacidade da criança ou do adolescente vítima ou testemunha de violência.

Art. 11. O depoimento especial reger-se-á por protocolos e,

\footnotetext{
${ }^{17}$ CEZAR, José Antônio Daltoé. A escuta de crianças e adolescentes em juízo. Uma questão legal ou um exercício de direitos? In Depoimento sem dano. Rio de Janeiro: Lumen Juris, 2010, p. 74.

${ }^{18}$ MELO, Eduardo Rezende. Crianças e adolescentes vítimas de abuso sexual e o direito. Uma análise crítica dos modelos de intervenção e da titulação a direitos sob o crivo histórico-comparativo à luz do debate em torno do depoimento especial. In: Depoimento especial de crianças e adolescente. Porto Alegre: Livraria do advogado, 2016, p. 71.
} 
sempre que possível, será realizado uma única vez, em sede de produção antecipada de prova judicial, garantida a ampla defesa do investigado.

$\S 10$ O depoimento especial seguirá o rito cautelar de antecipação de prova:

I - quando a criança ou o adolescente tiver menos de 7 (sete) anos;

II - em caso de violência sexual.

§ 2o Não será admitida a tomada de novo depoimento especial, salvo quando justificada a sua imprescindibilidade pela autoridade competente e houver a concordância da vítima ou da testemunha, ou de seu representante legal.

Assemelha-se, portanto, ao rito já previsto pela Recomendação no ${ }^{\circ} 33$ do Conselho Nacional Justiça, tratando-se da conferência de força legislativa a um ato administrativo, em âmbito interno. Apesar da necessidade de aperfeiçoamento do procedimento, é início da tentativa do legislador brasileiro de proteger o direito da criança em ser ouvida e respeitada, há muito já reconhecido internacionalmente.

\section{O SISTEMA INTERAMERICANO DE PROTEÇÃO AOS DIREITOS HUMANOS E A ADESÃO DO BRASIL À CORTE}

É a partir da garantia dos direitos fundamentais positivados constitucionalmente que surge a necessidade de proteção desses direitos nos sistemas internacionais regionais. Inserido nesse contexto, surge, no âmbito da Organização dos Estados Americanos, o Sistema Interamericano de Proteção dos Direitos Humanos, que possui como principal instrumento jurídico internacional a Convenção Americana de Direitos Humanos, assinada em 22 de novembro de 1969 em San José, Costa Rica.

Com o a finalidade de fiscalizar e fazer valer as disposições convencionadas, Convenção Americana de Direitos Humanos prevê dois mecanismos distintos: a Comissão e a Corte. A primeira faz recomendações aos Estados, solicita informações, aponta medidas, realiza estudos e envia relatórios anuais à Assembleia Geral da Organização dos Estados Americanos. A Corte, por sua vez, é o órgão jurisdicional do Sistema Interamericano de Proteção aos Direitos Humanos que analisa possíveis transgressões do tratado internacional, tendo competência consultiva e contenciosa. 
Segundo seu Estatuto ${ }^{19}$, a Corte Interamericana de Direitos Humanos é uma instituição judiciária autônoma cujo objetivo é a aplicação e a interpretação da Convenção Americana sobre Direitos Humanos, visando consolidar no continente americano e no âmbito das instituições democráticas, um regime de liberdade pessoal e de justiça social, fundado no respeito dos direitos essenciais do homem. Sediada em San José, na Costa Rica, e funcionando de forma efetiva desde 1980, a Corte é composta por juízes que "[...] reúnam as condições requeridas para o exercício das mais elevadas funções judiciais, de acordo com a lei do estado do qual sejam nacionais, ou do estado que os propuser como candidatos." ${ }^{20}$.

Segundo o artigo 67 da Convenção Americana de Direitos Humanos, a decisão final da Corte será definitiva e inapelável, cabendo a esta, motivada por uma das partes, interpretá-la em caso de divergência sobre o sentido ou alcance da sentença. E, se por ventura reconhecer que houve a infração a algum dispositivo da Convenção em sua sentença, determinará a adoção de medidas que se façam necessárias à restauração do direito violado, podendo até mesmo, condenar o Estado ao pagamento de uma compensação à vítima. ${ }^{21}$

O Brasil é Estado-membro da Organização dos Estados Americanos e ratificou a Convenção Americana de Direitos Humanos em novembro de $1992^{22}$. Ademais, o Estado brasileiro aceitou a jurisdição da Corte Interamericana de Direitos Humanos $^{23}$, reconhecendo sua competência como obrigatória, de pleno direito e por tempo indeterminado, em todos os casos que possuam relação com a interpretação

19 COMISSÃO INTERAERICANA DE DIREITOS HUMANOS. Estatuto da Corte Interamericana de Direitos Humanos. Disponível em: < https://www.cidh.oas.org/basicos/portugues/v.Estatuto.Corte.htm>. Acesso em: 16.set.2016.

${ }^{20}$ PLANALTO. Convenção Americana sobre Direitos Humanos (Pacto de São José da Costa Rica), de 22 de novembro de 1969. Decreto $n^{\circ}$ 678, de 6 de novembro de 1992. Disponível em: < http://www.planalto.gov. br/ccivil 03/decreto/D0678.htm > . Acesso em: 15.set.2016.

${ }^{21}$ PLANALTO. Convenção Americana sobre Direitos Humanos (Pacto de São José da Costa Rica), de 22 de novembro de 1969. Decreto $\mathrm{n}^{\circ} 678$, de 6 de novembro de 1992. Disponível em: <http://www.planalto.gov. br/ccivil_03/decreto/D0678.htm>. Acesso em: 15.set.2016.

${ }^{22}$ PLANALTO. Convenção Americana sobre Direitos Humanos (Pacto de São José da Costa Rica), de 22 de novembro de 1969. Decreto $\mathrm{n}^{\circ}$ 678, de 6 de novembro de 1992. Disponível em: < http://www.planalto.gov. br/ccivil_03/decreto/D0678.htm>. Acesso em: 15.set.2016.

${ }^{23}$ Destaca-se a atuação da Corte em face do Estado brasileiro no tocante a situação de adolescentes internados no "Complexo de Tatuapé" da FEBEM. "Em função das graves violações aos direitos humanos dos adolescentes lá internados, a pedido da Comissão Interamericana, a Ciorte Interamericana requereu ao Estado brasileiro, por meio de Resolução expedida em 17/11/2005, a adoção de medidas provisórias para a proteção da vida e a integridade pessoal dos adolescentes que residiam no "Complexo do Tatuapé" da FEBEM (Fundação Estadual do Bem-Estar do Menor de São Paulo) e das pessoas que ingressassem futuramente na qualidade de internos ao mencionado centro de internação." In: GOTTI, Alessandra. A proteção aos direitos da criança na jurisprudência da Corte Interamericana. In: PIOVESAN, Flavia; SOARES, Inês Virginia Prado. Impacto das decisões da Corte Interamericana de Direitos Humanos na jurisprudência do STF. Salvador: JusPodium, 2016, p. 375 . 
ou aplicação da Convenção Americana. ${ }^{24}$

De acordo com a Convenção Americana em seu artigo 61, apenas os Estadospartes e a Comissão Interamericana de Direitos Humanos têm direito a submeter um caso para que seja apreciado pela Corte.

São requisitos para a análise da petição pela Comissão, nos termos do artigo 46 da Convenção Americana de Direitos Humanos:

1.Para que uma petição ou comunicação apresentada de acordo com os artigos 44 ou 45 seja admitida pela Comissão, será necessário:

a. que hajam sido interpostos e esgotados os recursos da jurisdição interna, de acordo com os princípios de direito internacional geralmente reconhecidos;

b. que seja apresentada dentro do prazo de seis meses, a partir da data em que o presumido prejudicado em seus direitos tenha sido notificado da decisão definitiva;

c. que a matéria da petição ou comunicação não esteja pendente de outro processo de solução internacional; e

d. que, no caso do artigo 44, a petição contenha o nome, a nacionalidade, a profissão, o domicílio e a assinatura da pessoa ou pessoas ou do representante legal da entidade que submeter a petição.

2. As disposições das alíneas a e b do inciso 1 deste artigo não se aplicarão quando:

a. não existir, na legislação interna do Estado de que se tratar, o devido processo legal para a proteção do direito ou direitos que se alegue tenham sido violados;

b. não se houver permitido ao presumido prejudicado em seus direitos o acesso aos recursos da jurisdição interna, ou houver sido ele impedido de esgotá-los; e

c. houver demora injustificada na decisão sobre os mencionados recursos. ${ }^{25}$

Desta forma, a Comissão Interamericana de Direitos Humanos atua como órgão preliminar à jurisdição da Corte sendo a primeira a tomar conhecimento da denúncia e ficando responsável por proceder de maneira sistemática quando

${ }^{24}$ PLANALTO. Declaração de Reconhecimento da Competência Obrigatória da Corte Interamericana de Direitos Humanos, sob reserva de reciprocidade, em consonância com o art. 62 da Convenção Americana sobre Direitos Humanos (Pacto de São José), de 22 de novembro de 1969. Decreto $n^{\circ} 4.463$, de 8 de novembro de 2002. Disponível em: < http://www.planalto.gov.br/ccivil_03/decreto/2002/d4463.htm > . Acesso em: 16.set.2016.

25 PLANALTO. Convenção Americana sobre Direitos Humanos (Pacto de São José da Costa Rica), de 22 de novembro de 1969. Decreto $\mathrm{n}^{\circ} 678$, de 6 de novembro de 1992. Disponível em: <http://www.planalto.gov. br/ccivil_03/decreto/D0678.htm>. Acesso em: 15.set.2016. 
recebê-la.

Esse procedimento possui quatro fases descritas nos artigos 48 e $50 \mathrm{da}$ Convenção e que devem ser realizadas preliminarmente, antes da ação chegar à Corte. São elas: a admissibilidade, a conciliação, a do primeiro informe e por fim a fase do segundo informe ou a própria propositura da ação perante a Corte Interamericana de Direitos Humanos.

Conclui-se, portanto, que nem os particulares, nem as instituições privadas podem ingressar com pedidos diretamente à Corte, devendo, primeiramente, submeter o caso à Comissão Interamericana de Direitos Humanos que posteriormente submeterá à apreciação da Corte.

A denúncia, no entanto, pode ser feita por qualquer pessoa, grupo de pessoas ou entidade não governamental de Estado-parte da Convenção. Os Estadosparte também podem denunciar supostas ofensas incorridas por outros Estadosmembro, contanto que reconheçam, eles próprios, a competência do Sistema Interamericano para examinar tais violações.

\section{AS GARANTIAS JUDICIAS NO SISTEMA INTERAMERICANA DE DIREITOS HUMANOS}

Nos termos do artigo 8 da Convenção Americana sobre Direitos Humanos todos têm o direito a um julgamento justo, considerando-se "[p]ara os efeitos desta Convenção, [que] pessoa é todo ser humano" (artigo 1.2):

Artigo 8. Garantias judiciais:

1. Toda pessoa tem direito a ser ouvida, com as devidas garantias e dentro de um prazo razoável, por um juiz ou tribunal competente, independente e imparcial, estabelecido anteriormente por lei, na apuração de qualquer acusação penal formulada contra ela, ou para que se determinem seus direitos ou obrigações de natureza civil, trabalhista, fiscal ou de qualquer outra natureza. ${ }^{26}$

Resulta da jurisprudência interamericana o direito das vítimas de participar

\footnotetext{
${ }^{26}$ PLANALTO. Convenção Americana sobre Direitos Humanos (Pacto de São José da Costa Rica), de 22 de novembro de 1969. Decreto $\mathrm{n}^{\circ}$ 678, de 6 de novembro de 1992. Disponível em: <http://www.planalto.gov. br/ccivil_03/decreto/D0678.htm>. Acesso em: 15.set.2016.
} 
do inquérito e processo penal. A Corte afirma que as vítimas "devem ter possibilidades substanciais de serem ouvidas e agindo nos respectivos processos" ${ }^{27}$. A Corte também afirma, pela primeira vez no processo Radilla Pacheco versus México, que os Estados têm a obrigação de garantir que, em todas as fases do processo, as vítimas possam fazer declarações, receber informações, apresentar provas, fazer alegações e em suma, fazer valer os seus interesses ${ }^{28}$, tendo como finalidade o acesso à justiça, o conhecimento da verdade sobre o ocorrido e à outorga de uma reparação justa.

O entendimento da Corte quanto ao direito de ser ouvido, protegido no artigo 8.1 da Convenção, compreende o direito de todos a ter acesso ao tribunal ou órgão estadual competente para determinar seus direitos e obrigações. Neste sentido, o direito de ser ouvido implica

[...] por um lado, um âmbito formal e processual de assegurar o acesso ao órgão competente para determinar o direito que se reclama [...]. De outro lado, esse direito abarca um âmbito de proteção material que implica que o Estado garanta que a decisão que se produza através do procedimento satisfaça o fim para o qual foi concebido. Este último não significa que sempre deve ser acolhido, mas sim garantir a sua capacidade de produzir o resultado para o qual foi concebido. ${ }^{29}$ (tradução livre)

Segundo entendimento da Corte, para que o devido processo realmente exista, é necessário que os litigantes possam fazer valer seus direitos e defender os seus interesses de forma eficaz e em condições de igualdade processual com os demais. Desta forma, para que o processo alcance seus objetivos, é necessário

\footnotetext{
${ }^{27}$ A primeira decisão da Corte neste sentido foi no caso "Niños de la Calle". Ver a respeito em: Corte IDH. Caso de los "Niños de la Calle" (Villagrán Morales y otros) vs. Guatemala. Sentencia de 19 de noviembre de 1999. Disponível em: < http://www.corteidh.or.cr/docs/casos/articulos/Seriec_63_esp.pdf > . Acesso em: 13.set.2016.

28 "De conformidad con el derecho reconocido en el artículo 8.1 de la Convención Americana, en relación con el artículo 1.1 de la misma, este Tribunal ha establecido que los Estados tienen la obligación de garantizar que, en todas las etapas de los respectivos procesos, las víctimas puedan bacer planteamientos, recibir informaciones, aportar pruebas, formular alegaciones y, en sintesis, hacer valer sus interesses". Corte IDH. Caso Radilla Pacheco vs. México. Excepciones Preliminares, Fondo, Reparaciones y Costas. Sentencia de 23 de Noviembre de 2009. Disponível em: < http://www.corteidh.or.cr/docs/casos/articulos/seriec_209_esp. pdf>. Acesso em: 13.set.2016, p. 71.

29 ".... implica, por un lado, un ámbito formal y procesal de asegurar el acceso al órgano competente para que determine el derecho que se reclama [...]. Por otra parte, ese derecho abarca un ámbito de protección material que implica que el Estado garantice que la decisión que se produzca a través del procedimiento satisfaga el fin para el cual fue concebido. Esto último no significa que siempre deba ser acogido sino que se debe garantizar su capacidad para producir el resultado para el que fue concebido." Corte IDH. Caso del Tribunal Constitucional (Camba Campos y otros) vs. Ecuador. Excepciones Preliminares, Fondo, Reparaciones y Costas. Sentencia de 28 de agosto de 2013. Disponível em: < http://www.corteidh.or.cr/docs/ casos/articulos/seriec_268_esp.pdf >. Acesso em: 06.set.2016, p. 54, § 181.
} 
que o sistema corrija eventuais desvantagens, pois, se ausente tais compensações, dificilmente seria possível dizer que aqueles que estão em desvantagem desfrutam de um verdadeiro acesso à justiça e beneficiam-se de um processo devido com igualdade em relação àqueles que não possuem essas desvantagens.

A Corte Interamericana tem assentado que o direito ao devido processo legal, consagrado na Convenção Americana, refere-se a todos os requisitos a serem observados nas fases processuais "a fim de que as pessoas possam defender adequadamente os seus direitos diante de qualquer ato estatal que possa afetá-la, adotado por qualquer autoridade pública, seja administrativa, legislativa ou judicial". Ou seja, "qualquer ato ou omissão dos órgãos do Estado em um processo, quer sanção administrativa ou judicial, deve respeitar o devido processo". ${ }^{30}$

Para o alcance destes objetivos, a Corte assinalou que

[...] o processo deve reconhecer e corrigir eventuais desvantagens reais dos que são levados à justiça. Assim se aplica o princípio da igualdade perante a lei e os tribunais e a correlativa proibição de discriminação. A presença de condições de desigualdade real obriga a adoptar medidas de compensação para ajudar a reduzir ou eliminar os obstáculos e deficiências que prejudicam ou reduzem a defesa eficaz dos próprios interesses..$^{31}$ (tradução livre)

O entendimento reafirma a preocupação da Corte Interamericana em garantir e direcionar o exemplo a ser cumprido pelos Estados signatários do Pacto de San Jose da Costa Rica no devido processo legal.

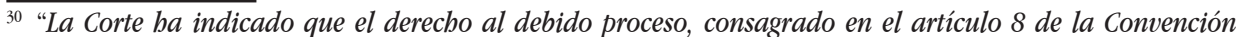
Americana, se refiere al conjunto de requisitos que deben observarse en las instancias procesales a efectos de que las personas estén en condiciones de defender adecuadamente sus derechos ante cualquier acto del Estado, adoptado por cualquier autoridad pública, sea administrativa, legislativa o judicial, que pueda afectarlos [...] cualquier actuación u omisión de los órganos estatales dentro de un proceso, sea administrativo sancionatorio o jurisdiccional, debe respetar el debido proceso legal." Corte IDH. Caso Familia Pacheco Tineo vs. Bolivia. Excepciones Preliminares, Fondo, Reparaciones y Costas. Sentencia de 25 de noviembre de 2013. Corte IDH. Disponível em: < http://www.corteidh.or.cr/docs/casos/articulos/ seriec_272_esp.pdf >. Acesso em: 13.set.2016, p. 43, § 130.

31 "[...] el proceso debe reconocer y resolver los factores de desigualdad real de quienes son llevados ante la justicia. Es así como se atiende el principio de igualdad ante la ley y los tribunales y a la correlativa probibición de discriminación. La presencia de condiciones de desigualdade real obliga a adoptar medidas de compensación que contribuyan a reducir o eliminar los obstáculos y deficiencias que impidan o reduzcan la defensa eficaz de los propios interesses." Corte IDH. El Derecho a la Información sobre la Asistencia Consular en el Marco de las Garantías del Debido Proceso Legal. Opinión Consultiva OC-16/99 de 1 de octubre de 1999. Disponível em: < http://www.corteidh.or.cr/docs/opiniones/seriea_16_esp.pdf > Acesso em: 13.set.2016, p. 69, § 119.
} 


\subsection{AS GARANTIAS DA CRIANÇA DE SER OUVIDA NO SISTEMA INTERAMERICANO E A JURISPRUDÊNCIA DA CORTE}

O Sistema Interamericano, tal como reconhecido na Convenção sobre os Direitos da Criança ${ }^{32}$, garante que "as crianças têm direitos que se aplicam a todos os seres humanos - menores ou adultos - e também direitos especiais decorrentes de sua condição, correspondentes a deveres específicos da família, da sociedade e do Estado" 33 , pois, "em razão a sua imaturidade e vulnerabilidade, necessitam de proteção para garantir o exercício dos seus direitos" ${ }^{\text {"34 }}$, levando-se em conta 0 princípio do interesse da criança. ${ }^{35}$

As garantias judiciais consagradas na Convenção devem ser correlacionadas com os direitos específicos também estabelecidos no artigo 19 do documento, irradiando efeitos nos processos administrativos ou judiciais em que são discutidos direitos de uma criança. Segundo o artigo 19, da Convenção Americana, "[t]oda criança tem direito às medidas de proteção que a sua condição de menor requer por parte da sua família, da sociedade e do Estado".

Ademais, a Convenção Americana que "toda pessoa tem o direito ao reconhecimento de sua personalidade jurídica, estendendo essa interpretação ás

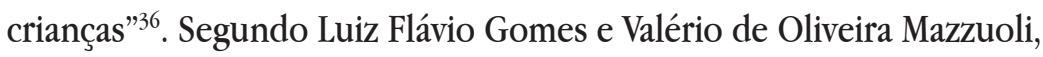

[...] o intuito do art. $3^{\circ}$ em comento foi o de abolir, no Continente Americano, a "personalidade jurídica sub conditione" (ou

\footnotetext{
32 PLANALTO. Convenção sobre os Direitos da Criança. Decreto no 99.710, de 21 de novembro de 1990. Disponível em: <http://www.planalto.gov.br/ccivil_03/decreto/1990-1994/D99710.htm>. Acesso em: 06.set.2016.

33 "[L]os niños poseen los derechos que corresponden a todos los seres bumanos - menores y adultos - y tienen además derechos especiales derivados de su condición, a los que corresponden deberes específicos de la familia, la sociedad y el Estado", porque los niños. "[e]n razón de su inmadurez y vulnerabilidad, requieren protección que garantice el ejercicio de sus derechos." Corte IDH. Condición Jurídica y Derechos Humanos del Niño. Opinión Consultiva OC-17/02 del 28 de agosto de 2002. Disponível em: <http://www. corteidh.or.cr/docs/opiniones/seriea_17_esp.pdf>. Acesso em: 06.set.2016, p. 60, \$ 54 .

34 "[e]n razón de su inmadurez y vulnerabilidad, requieren protección que garantice el ejercicio de sus derechos." Corte IDH. Condición Jurídica y Derechos Humanos del Niño. Opinión Consultiva OC-17/02 del 28 de agosto de 2002. Disponível em: < http://www.corteidh.or.cr/docs/opiniones/seriea_17_esp.pdf > . Acesso em: 06.set.2016, p. 72, $\$ 93$.

35 Conforme julgado da Corte IDH. "[...] los niños y las niñas son titulares de los derechos establecidos en la Convención Americana, además de contar con las medidas especiales de protección contempladas en su artículo 19, las cuales deben ser definidas según las circunstancias particulares de cada caso concreto. La adopción de medidas especiales para la protección del niño corresponde tanto al Estado como a la familia, la comunidad y la sociedad a la que aquél pertenece." Corte IDH. Caso Furlan y Familiares vs. Argentina. Excepciones Preliminares, Fondo, Reparaciones y Costas. Sentencia de 31 de agosto de 2012. Disponível em: $<$ http://www.corteidh.or.cr/docs/casos/articulos/seriec_246_esp.pdf > . Acesso em: 06.set.2016, p. 43, § 125.

36 PLANALTO. Convenção Americana sobre Direitos Humanos (Pacto de São José da Costa Rica), de 22 de novembro de 1969. Decreto $\mathrm{n}^{\circ} 678$, de 6 de novembro de 1992. Disponível em: <http://www.planalto.gov. br/ccivil_03/decreto/D0678.htm > . Acesso em: 15.set.2016.
} 
"personalidade jurídica condicionada"), segundo a qual se reconhece tal personalidade às pessoas (e sua consequente capacidade para vindicar direitos), mas desde que satisfeitas determinadas condições impostas pelo Estado. São dramáticos os exemplos de reconhecimento da personalidade jurídica sub conditione, sendo o mais bestial deles o que ocorreu no período do Holocausto, em que o governo de Hitler condicionava a titularidade de direitos a pertencer o individuo à "raça pura ariana", excluindo por assassinato todos os demais que nesta categoria não enquadravam. ${ }^{37}$

A Corte Interamericana também destaca que o artigo $8^{\circ}$ da Convenção Americana deve ser interpretado à luz do artigo 12 da Convenção sobre os Direitos da Criança, que contém as disposições adequadas sobre o direito das crianças de ser ouvido, com o objetivo de que a intervenção da criança se ajuste às condições deste e não prejudique o seu interesse genuíno. ${ }^{38}$

Artigo 12. 1. Os Estados Parte assegurarão à criança que estiver capacitada a formular seus próprios juízos o direito de expressar suas opiniões livremente sobre todos os assuntos relacionados com a criança, levando-se devidamente em consideração essas opiniões, em função da idade e maturidade da criança. 2 . Com tal propósito, se proporcionará à criança, em particular, a oportunidade de ser ouvida em todo processo judicial ou administrativo que afete a mesma, quer diretamente quer por intermédio de um representante ou órgão apropriado, em conformidade com as regras processuais da legislação nacional. ${ }^{39}$

Sobre este ponto, o Comitê de Direitos da Criança ${ }^{40}$ das Nações Unidas ressaltou em suas Observações Gerais $\mathrm{n}^{0} 12$ de 2009, a relação entre o interesse superior da criança e o direito a ser ouvido, ao afirmar que não é possível uma

37 GOMES, Luiz Flávio; MAZZUOLI, Valério de Oliveira. Comentários à Convenção Americana sobre Direitos Humanos, Pacto de San Jose da Costa Rica. São Paulo: Revista dos Tribunais, 2013, p. 38.

${ }^{38}$ Corte IDH. Caso Atala Riffo y Niñas vs. Chile. Fondo, Reparaciones y Costas. Sentencia del 24 de febrero de 2012. Disponível em: < http://corteidh.or.cr/docs/casos/articulos/seriec_239_esp.pdf> . Acesso em: 06. set. 2016, p. $62, \S 196$.

39 PLANALTO. Convenção sobre os Direitos da Criança. Decreto $n^{0} 99.710$, de 21 de novembro de 1990. Disponível em: < http://www.planalto.gov.br/ccivil_03/decreto/1990-1994/D99710.htm > . Acesso em: 06. set. 2016.

${ }^{40}$ O Comitê dos Direitos da Criança é o órgão criado em virtude do art. 43 da Convenção sobre os Direitos da Criança com o objetivo de controlar a aplicação, pelos Estados Partes, das disposições desta Convenção, bem como dos seus dois Protocolos Facultativos (relativos ao Envolvimento de Crianças em Conflitos Armados e à Venda de Crianças, Prostituição Infantil e Pornografia Infantil). 
aplicação correta do art. $3^{41}$ se não for respeitado os procedimentos do art. $12^{42}$, ambos da Convenção sobre os Direitos da Criança, uma vez que aquele dispositivo reforça a funcionalidade da participação da criança em decisões que afetam sua vida.

A Corte Interamericana explica que as condições em que uma criança participa de um processo não são as mesmas de um adulto.

[...] os direitos processuais e suas correspondentes garantias aplicam-se a todas as pessoas, mas no caso de crianças, o exercício desses direitos supõe, em razão das condições especiais em que os menores se encontram, a adoção de certas medidas específicas com o objetivo de efetivamente gozem desses direitos e garantias. ${ }^{43}$ (tradução livre)

Ademais, a Corte se manifestou no caso Dacosta Cadogan vs. Barbados sobre a obrigação dos juízes dos Estados de adotar medidas para assegurar um julgamento justo.

As garantias podem ser determinadas pelo tribunal atendendo às particularidades de cada caso concreto. Ou seja, todo juiz tem a obrigação de garantir que o processo seja realizado com o devido respeito as garantias judiciais necessárias para

\footnotetext{
$\overline{41}$ Artigo 3. 1. Todas as ações relativas às crianças, levadas a efeito por instituições públicas ou privadas de bem estar social, tribunais, autoridades administrativas ou órgãos legislativos, devem considerar, primordialmente, $\mathrm{o}$ interesse maior da criança. 2. Os Estados Partes se comprometem a assegurar à criança a proteção e o cuidado que sejam necessários para seu bem-estar, levando em consideração os direitos e deveres de seus pais, tutores ou outras pessoas responsáveis por ela perante a lei e, com essa finalidade, tomarão todas as medidas legislativas e administrativas adequadas. 3. Os Estados Partes se certificarão de que as instituições, os serviços e os estabelecimentos encarregados do cuidado ou da proteção das crianças cumpram com os padrões estabelecidos pelas autoridades competentes, especialmente no que diz respeito à segurança e à saúde das crianças, ao número e à competência de seu pessoal e à existência de supervisão adequada. PLANALTO. Convenção sobre os Direitos da Criança. Decreto n ${ }^{0}$ 99.710, de 21 de novembro de 1990. Disponível em: $<$ http://www.planalto.gov.br/ccivil_03/decreto/1990-1994/D99710.htm> . Acesso em: 06.set.2016.

${ }_{42}$ "No existe tensión entre los artículos 3 y 12, sino solamente complementariedad entre los dos principios generales: uno establece el objetivo de alcanzar el interés superior del niño y el otro ofrece la metodología para lograr el objetivo de escuchar al niño o a los niños. En realidad, no es posible una aplicación correcta del artículo 3 si no se respetan los componentes del artículo 12. Del mismo modo, el artículo 3 refuerza la funcionalidad del artículo 12 al facilitar el papel esencial de los niños en todas las decisiones que afecten a su vida." ACNUR. Comité de los Derechos del Niño. Observación General No 12 (2009). El derecho del niño a ser escuchado. Disponível em: <http://www.acnur.org/t3/fileadmin/Documentos/BDL/2011/7532. pdf?view $=1>$. Acesso em: 16.set.2016, p. 19, $\$ 74$.

43 "[...] si bien los derechos procesales y sus correlativas garantías son aplicables a todas las personas, en el caso de los niños el ejercicio de aquéllos supone, por las condiciones especiales en las que se encuentran los menores, la adopción de ciertas medidas específicas con el propósito de que gocen efectivamente de dichos derechos y garantias." Corte IDH. Condición Jurídica y Derechos Humanos del Niño. Opinión Consultiva OC17/02 del 28 de agosto de 2002. Disponível em: < http://www.corteidh.or.cr/docs/opiniones/seriea_17_esp. pdf >. Acesso em: 06.set.2016, p. 73, §98.
} 
assegurar um juízo justo. ${ }^{44}$ (tradução livre)

De modo específico, no caso Atala Riffo y Niñas vs. Chile a Corte retoma as recomendações do Comitê dos Direitos das Crianças das Nações Unidas segundo o qual

[...] "não se pode partir da premissa de que uma criança é incapaz de expressas suas próprias opiniões"; ademais "a criança não deve ter necessariamente um conhecimento exaustivo de todos os aspectos do assunto que o afeta, mas uma compreensão suficiente para ser capaz de formar adequadamente um juízo próprio sobre o assunto"; "a criança pode expressar suas opiniões sem pressão e pode escolher se quer ou não exercer seu direito de ser ouvido"; "a concretização do direito da criança em expressar suas opinióes exige que os responsáveis de ouvir a criança e os pais ou tutores informem à criança dos assuntos, as opções e as possíveis decisões que podem ser adotadas e seus consequências"; "a capacidade da criança [...] deve ser avaliada para se ter devidamente em conta suas opiniões ou para comunicar à criança sobre a influência que suas opiniões possuem sobre o resultado do processo"; e "os níveis de compreensão das crianças não estão ligados de maneira uniforma a sua idade biológica", a maturidade das crianças deve ser medida a partir da capacidade "para expressar suas opiniões sobre questões de forma racional e independente". ${ }^{45}$ (tradução livre)

$\overline{44}$ "[...] las debidas garantías"podrán ser determinadas por el tribunal atendiendo a las particularidades de cada caso concreto. Es decir, todo juez tiene la obligación de asegurar que los procesos se lleven a cabo con el debido respeto de aquellas garantías judiciales, que sean necesarias para asegurar un juicio justo". Corte IDH. Caso Dacosta Cadogan vs. Barbados. Excepciones Preliminares, Fondo, Reparaciones y Costas. Sentencia de 24 de Septiembre de 2009. Disponível em: < http://www.corteidh.or.cr/docs/casos/articulos/seriec_204_ esp.pdf > . Acesso em: 06.set.2016, p. 24, §84.

45 "En el Caso Atala Riffo y Niñas Vs. Chile, la Corte retoma las especificaciones del Comité de los Derechos del Niño según las cuales "no puede partir[se] de la premisa de que un niño es incapaz de expresar sus propias opiniones"; además, "el niño no debe tener necesariamente un conocimiento exhaustivo de todos los aspectos del asunto que lo afecta, sino una comprensión suficiente para ser capaz de formarse adecuadamente un juicio propio sobre el asunto"; "el niño puede expresar sus opiniones sin presión y puede escoger si quiere o no ejercer su derecho a ser escuchado"; "la realización del derecho del niño a expresar sus opiniones exige que los responsables de escuchar al niño y los padres o tutores informen al niño de los asuntos, las opciones y las posibles decisiones que pueden adoptarse y sus consecuencias"; "la capacidad del niño [...] debe ser evaluada para tener debidamente en cuenta sus opiniones o para comunicar al niño la influencia que ban tenido esas opiniones en el resultado del proceso"; y "los niveles de comprensión de los niños no van ligados de manera uniforme a su edad biológica", por lo que la madurez de los niños o niñas debe medirse a partir de la capacidad "para expresar sus opiniones sobre las cuestiones de forma razonable e independiente." Corte IDH. Caso Atala Riffo y Niñas vs. Chile. Fondo, Reparaciones y Costas. Sentencia del 24 de febrero de 2012. Disponível em: < http://corteidh.or.cr/docs/casos/articulos/seriec_239_esp.pdf > . Acesso em: 06.set.2016, p. 63, § 198. 
A Corte de San José recorda, considerando, em particular, a Convenção sobre os Direitos da Criança e no disposto no artigo $14^{46}$ do Pacto Internacional sobre Direitos Civis e Políticos das Nações Unidas, que intervenção da criança deve ser ajustada às suas condições, sem prejudicar o seu interesse. Além disso, o grau de desenvolvimento físico e intelectual, a experiência e as informações que as crianças possuem devem ser utilizados como parâmetro para determinar a participação da criança no processo.

Assim, o operador do direito deve considerar as condições específicas do infante e seus interesses para decidir sobre a sua participação $0^{47}$, conforme o caso, na determinação de seus direitos, assim

[...] a Corte reitera que as crianças exerçam seus direitos de maneira progressiva na medida que desenvolvam um maior nível de autonomia pessoal. Como consequência, o operador do direito, seja no âmbito administrativo ou no judicial deverá levar em consideração as condições especificas do menor de idade e seu maior interesse para determinar a sua participação, que corresponda à determinação de seus direitos. Com essa ponderação buscar-se-á o maior acesso do menor de idade, na medido do possível, ao exame de seu próprio caso. ${ }^{48}$ (tradução livre)

\footnotetext{
$\overline{46}$ "Artigo 14. 1. Todas as pessoas são iguais perante os tribunais e as cortes de justiça. Toda pessoa terá o direito de ser ouvida publicamente e com devidas garantias por um tribunal competente, independente e imparcial, estabelecido por lei, na apuração de qualquer acusação de caráter penal formulada contra ela ou na determinação de seus direitos e obrigações de caráter civil. [...]" PLANALTO. Pacto Internacional sobre Direitos Civis e Políticos. Decreto $\mathrm{n}^{0}$ 592, de 6 de julho de 1992. Disponível em: < http://www.planalto.gov. br/ccivil_03/decreto/1990-1994/d0592.htm >. Acesso em: 15.set.2016.

47 "Por otra parte, la Corte reitera que los niños y las niñas ejercen sus derechos de manera progresiva a medida que desarrollan un mayor nivel de autonomía personal [...]En consecuencia, el aplicador del derecho, sea en el ámbito administrativo o en el judicial, deberá tomar en consideración las condiciones específicas del menor de edad y su interés superior para acordar la participación de éste, según corresponda, en la determinación de sus derechos. En esta ponderación se procurará el mayor acceso del menor de edad, en la medida de lo posible, al examen de su próprio caso. Asimismo, la Corte considera que las niñas y los niños deben ser informados de su derecho a ser escuchados directamente o por medio de un representante, si así lo desean. Al respecto, en casos en que se presenten conflictos de intereses entre la madre y el padre, es necesario que el Estado garantice, en lo posible, que los intereses del menor de edad sean representados por alguien ajeno a dicho conflicto." Corte IDH. Caso Atala Riffo y Niñas vs. Chile. Fondo, Reparaciones y Costas. Sentencia del 24 de febrero de 2012. Disponível em: < http://corteidh.or.cr/docs/casos/articulos/ seriec_239_esp.pdf>. Acesso em: 06.set.2016, p. 64, § 199.

48 ".... la Corte reitera que los niños y las niñas ejercen sus derechos de manera progresiva a medida que desarrollan un mayor nivel de autonomía personal. En consecuencia, el aplicador del derecho, sea en el ámbito administrativo o en el judicial, deberá tomar en consideración las condiciones específicas del menor de edad y su interés superior para acordar la participación de éste, según corresponda, en la determinación de sus derechos. En esta ponderación se procurará el mayor acceso del menor de edad, en la medida de lo posible, al examen de su propio caso." Corte IDH. Caso Furlan y Familiares vs. Argentina. Excepciones Preliminares, Fondo, Reparaciones y Costas. Sentencia de 31 de agosto de 2012. Disponível em: < http://www. corteidh.or.cr/docs/casos/articulos/seriec_246_esp.pdf>. Acesso em: 06.set.2016, p. 74, § 230.
} 
Não basta escutar a criança. Suas opiniões devem ser seriamente consideradas a partir do momento em que é considerado capaz de formar seu próprio juízo. Neste sentido, importante salientar que apesar de ser também garantido à criança com deficiência o direito de ser ouvida, tais formalidades não são igualmente aplicáveis, exigindo-se maior cautela e assistência adequada de acordo com a sua deficiência e idade ${ }^{49}$.

\section{CONCLUSÃO}

De todo o exposto, interpretando o direito da criança em ser ouvidas em todos os processos penais em que figure como vítima, a dispensa arbitrária de sua opinião enseja o acionamento da Comissão Interamericana de Direitos Humanos, com a consequente anulação do processo.

Como dito, a emissão da opinião não é obrigatória para a criança, devendo ser respeitada, inclusive, o seu direito em querer ou não falar sobre os fatos dos quais foi vítima. Entretanto, em manifestando sua vontade de falar, em especial como vítima, seu direito impõe ao Poder Judiciário o dever de sua oitiva.

Neste sentido, há possibilidade de pessoa que não completou 18 anos de idade acionar a Comissão, como destacado no caso Georgina Gamboa García y familiares versus Perú, em que a senhorita Georgina, quando tinha apenas 17 anos de idade, relata ter sido vítima de abusos sexuais não investigados devidamente, e, portanto, não punidos, pelo Estado do Peru. No Relatório de 24 de julho de 2014, a Comissão entendeu por admitir e remeter à Corte Interamericana de Direitos Humanos o apelo, tendo a peticionária como representante a Comissão de Direitos Humanos do Peru.

Pode-se afirmar que a partir da decisão do Brasil em aceitar a competência contenciosa da Corte Interamericana de Direitos Humanos, dá-se início à expansão do pensamento jurídico, alinhando-se com o movimento universal de internacionalização dos direitos humanos.

\footnotetext{
${ }^{49}$ A Corte determinou no caso Furlan y Familiares vs. Argentina que as crianças com deficiência possuem direito de expressar sua opinião, que receberá a devida consideração, levando-se em conta sua idade e maturidade, bem como possuem o direito de receber assistência adequada de acordo com a sua deficiência e idade. Ver a respeito em: Corte IDH. Caso Furlan y Familiares vs. Argentina. Excepciones Preliminares, Fondo, Reparaciones y Costas. Sentencia de 31 de agosto de 2012. Disponível em: < http://www.corteidh.or.cr/docs/ casos/articulos/seriec_246_esp.pdf>. Acesso em: 06.set.2016, p. 74, § 230.
} 
A jurisprudência da Corte Interamericana ressalta a importância do resguardo ao direito da criança de ser ouvida. Neste sentido, a violação desta garantia dos infantes pelo Brasil ou outro Estado-parte, certamente, enseja o acionamento dos mecanismos internacionais, desde que implementados os requisitos presentes no Pacto de San Jose da Costa Rica, conforme exposto. O acolhimento da petição, seguramente, traria a consequência da anulação do processo julgado sem o devido respeito ao direito da oitiva da criança.

\section{REFERÊNCIAS}

ACNUR. Comité de los Derechos del Niño. Observación General No 12 (2009). El derecho del niño a ser escuchado. Disponível em: < http://www.acnur.org/ t3/fileadmin/Documentos/BDL/2011/7532.pdf?view=1 > . Acesso em: 16. set. 2016.

BARROS, Flaviane de Magalhães. A participação da vítima no processo penal. Rio de Janeiro: Lumen Juris, 2008.

BEDÊ JUNIOR, Américo; SENNA, Gustavo. Princípios do processo penal. São Paulo: RT, 2009.

CEZAR, José Antônio Daltoé. A escuta de crianças e adolescentes em juízo: uma questão legal ou um exercício de direitos? In: DEPOIMENTO sem dano. Rio de Janeiro: Lumen Juris, 2010.

COMISSÃO INTERAERICANA DE DIREITOS HUMANOS. Estatuto da Corte Interamericana de Direitos Humanos. Disponível em: < https://www.cidh.oas. org/basicos/portugues/v.Estatuto.Corte.htm> . Acesso em: 16. set. 2016.

CORTE IDH. Caso Atala Riffo y Niñas vs. Chile. Fondo, Reparaciones y Costas. Sentencia del 24 de febrero de 2012. Disponível em: < http://corteidh.or.cr/docs/ casos/articulos/seriec_239_esp.pdf > . Acesso em: 06. set. 2016.

CORTE IDH. Caso Dacosta Cadogan vs. Barbados. Excepciones Preliminares, Fondo, Reparaciones y Costas. Sentencia de 24 de Septiembre de 2009. Disponível em: < http://www.corteidh.or.cr/docs/casos/articulos/seriec_204_esp.pdf > . Acesso em: 06. set. 2016.

CORTE IDH. Caso de los "Niños de la Calle" (Villagrán Morales y otros) vs. 
Guatemala. Sentencia de 19 de noviembre de 1999. Disponível em: < http://www. corteidh.or.cr/docs/casos/articulos/Seriec_63_esp.pdf>. Acesso em: 13. set. 2016.

CORTE IDH. Caso del Tribunal Constitucional (Camba Campos y otros) vs. Ecuador. Excepciones Preliminares, Fondo, Reparaciones y Costas. Sentencia de 28 de agosto de 2013. Disponível em: < http://www.corteidh.or.cr/docs/casos/articulos/ seriec_268_esp.pdf > . Acesso em: 06. set. 2016.

CORTE IDH. Caso Familia Pacheco Tineo vs. Bolivia. Excepciones Preliminares, Fondo, Reparaciones y Costas. Sentencia de 25 de noviembre de 2013. Corte IDH. Disponível em: <http://www.corteidh.or.cr/docs/casos/articulos/seriec_272_esp. pdf $>$. Acesso em: 13. set. 2016.

CORTE IDH. Caso Furlan y Familiares vs. Argentina. Excepciones Preliminares, Fondo, Reparaciones y Costas. Sentencia de 31 de agosto de 2012. Disponível em: $<$ http://www.corteidh.or.cr/docs/casos/articulos/seriec_246_esp.pdf > . Acesso em: 06. set. 2016, p. $43, \S 125$.

CORTE IDH. Caso Radilla Pacheco vs. México. Excepciones Preliminares, Fondo, Reparaciones y Costas. Sentencia de 23 de Noviembre de 2009. Disponível em: $<$ http://www.corteidh.or.cr/docs/casos/articulos/seriec_209_esp.pdf > . Acesso em: 13. set. 2016.

CORTE IDH. Condición Jurídica y Derechos Humanos del Niño. Opinión Consultiva OC-17/02 del 28 de agosto de 2002. Disponível em: < http://www. corteidh.or.cr/docs/opiniones/seriea_17_esp.pdf > . Acesso em: 06. set. 2016.

CORTE IDH. El Derecho a la Información sobre la Asistencia Consular en el Marco de las Garantías del Debido Proceso Legal. Opinión Consultiva OC16/99 de 1 de octubre de 1999. Disponível em: <http://www.corteidh.or.cr/docs/ opiniones/seriea_16_esp.pdf > . Acesso em: 13. set. 2016.

CORTE IDH. Opinión Consultiva OC-17/2002 de e 28 de agosto de 2002, Solicitada por la Comisión Interamericana de Derechos Humanos. Disponível em: < http://www.corteidh.or.cr/docs/opiniones/seriea_17_esp.pdf $>$. Acesso em: 20. set. 2016.

GOMES, Luiz Flávio; MAZZUOLI, Valério de Oliveira. Comentários à Convenção Americana sobre Direitos Humanos, Pacto de San Jose da Costa Rica. São Paulo: Revista dos Tribunais, 2013. 
GOTTI, Alessandra. A proteção aos direitos da criança na jurisprudência da Corte Interamericana. In: PIOVESAN, Flavia; SOARES, Inês Virginia Prado. Impacto das decisões da Corte Interamericana de Direitos Humanos na jurisprudência do STF. Salvador: JusPodium, 2016.

MELO, Eduardo Rezende. Crianças e adolescentes vítimas de abuso sexual e o direito. Uma análise crítica dos modelos de intervenção e da titulação a direitos sob o crivo histórico-comparativo à luz do debate em torno do depoimento especial. In: DEPOIMENTO especial de crianças e adolescente. Porto Alegre: Livraria do advogado, 2016.

NUCCI, Guilherme de Souza. Código de processo penal comentado. São Paulo: RT, 2012.

PACELLI, Eugênio; FISCHER, Douglas. Comentários ao Código de Processo Penal e sua jurisprudência. 5. ed. São Paulo: Atlas, 2013, p. 417.

PLANALTO. Convenção Americana sobre Direitos Humanos (Pacto de São José da Costa Rica), de 22 de novembro de 1969. Decreto $n^{0}$ 678, de 6 de novembro de 1992. Disponível em: <http://www.planalto.gov.br/ccivil_03/decreto/D0678. htm >. Acesso em: 15. set. 2016.

PLANALTO. Convenção sobre os Direitos da Criança. Decreto no 99.710, de 21 de novembro de 1990. Disponível em: < http://www.planalto.gov.br/ccivil_03/ decreto/1990-1994/D99710.htm>. Acesso em: 06.set. 2016.

PLANALTO. Declaração de Reconhecimento da Competência Obrigatória da Corte Interamericana de Direitos Humanos, sob reserva de reciprocidade, em consonância com o art. 62 da Convenção Americana sobre Direitos Humanos (Pacto de São José), de 22 de novembro de 1969. Decreto $\mathrm{n}^{0} 4.463$, de 8 de novembro de 2002. Disponível em: < http://www.planalto.gov.br/ccivil_03/ decreto/2002/d4463.htm > . Acesso em: 16. set. 2016.

PLANALTO. Pacto Internacional sobre Direitos Civis e Políticos. Decreto $\mathrm{n}^{\mathrm{o}}$ 592, de 6 de julho de 1992. Disponível em: < http://www.planalto.gov.br/ccivil_03/ decreto/1990-1994/d0592.htm > . Acesso em: 15. set. 2016.

PLANALTO. Protocolo Facultativo à Convenção sobre os Direitos da Criança referente à venda de crianças, à prostituição infantil e à pornografia infantil. Decreto $\mathrm{n}^{0} 5.007$, de 8 de março de 2004. Disponível em: < http://www.planalto.gov. 
br/ccivil_03/_ato2004-2006/2004/decreto/d5007.htm >. Acesso em: 20 set. 2016. THÈRY, Irene. Nouveaux droits de l'enfant, la potion magique? Paris: Esprit, $n$. 180 (3/4) (mars-avril 1992).

UNITED NATIONS. Committee on the Rights of the child. Fifty-first session. Geneva, 25 May-12 June 2009. Disponível em: http://www2.ohchr.org/english/ bodies/crc/docs/AdvanceVersions/CRC-C-GC-12.pdf > . Acesso em: 16. set. 2016.

ZEHR, Howard. Justiça Restaurativa. São Paulo: Palas Athena, 2012.

Recebido em: 18 de setembro de 2017 Aceito em: 13 de dezembro de 2017 